Running Head: EROTICISM VERSUS NURTURANCE

\title{
Eroticism versus Nurturance: How Eroticism and Nurturance Differs in Polyamorous and Monogamous Relationships
}

\author{
Rhonda N. Balzarini ${ }^{1}$, Christoffer Dharma ${ }^{2}$, Amy Muise ${ }^{1}, \&$ Taylor Kohut $^{2}$, \\ ${ }^{1}$ Department of Psychology, York University, Toronto, ON, Canada \\ ${ }^{2}$ Department of Psychology, University of Western Ontario, London, ON, Canada
}

Correspondence concerning this article should be addressed to Rhonda Balzarini, Department of Psychology Main Office, Behavioural Science Building, York University, Toronto, Ontario, Canada M3J 1P3. E-mail: balzarinir@gmail.com

Contributions were as follows: RNB was in charge of conceptualization, data collection, data curation, methodology, and project administration. Formal analyses and verification of statistics reported were completed by $\mathrm{RNB}$ and $\mathrm{CD}$. RNB was responsible for writing the original draft of the manuscript and prepared the components for the Open Science Framework. All authors assisted with developing the analytic strategy and editing the manuscript. 


\begin{abstract}
Romantic partners provide both erotic and nurturing experiences, though these may emerge more strongly in different phases of a relationship. Unlike individuals in monogamous relationships, those in polyamorous relationships can pursue multiple romantic relationships simultaneously, potentially allowing them to experience higher levels of eroticism and nurturance. This research examined eroticism and nurturance among individuals in polyamorous and monogamous relationships. As expected, polyamorous participants experienced less eroticism but more nurturance in their relationships with their primary partner compared to secondary. Furthermore, people in polyamorous relationships reported more nurturance with primary partners and eroticism with secondary partners compared to people in monogamous relationships. These findings suggest that polyamory may provide a unique opportunity for individuals to experience both eroticism and nurturance simultaneously.

Keywords: polyamory; monogamy; nurturance; eroticism; relationship length
\end{abstract}


Eroticism versus Nurturance: How Eroticism and Nurturance Differs in Polyamorous and Monogamous Relationships

Romantic relationships are important to health and well-being (Coombs, 1991; Lillard \& Waite, 1995; Putzke, Elliott, \& Richards, 2001; Simon, 2002), in part because they often meet people's needs for emotional support, care, and sexual gratification (Hazan \& Shaver, 1994). However, fulfilling these needs simultaneously can be challenging, as the experience of eroticism (i.e., feeling of arousal, passion, lust, sexual pleasure) and nurturance (i.e., feelings of intimacy, warmth and love) often follow different time courses in a relationship (Hatfield, Traupmann, \& Sprecher, 1984; Sprecher \& Regan, 1998; Tennov, 1979; Winston, 2004). As a result, individuals in relationships are often stuck trying to balance their need for eroticism and their need for nurturance (Hazan \& Shaver, 1994), as experiences of eroticism are more prominent in the early stages, and experiences of nurturance develop over time as erotic desires decline. People in polyamorous relationships - relationships that involve consensual intimate relationships with more than one partner-may seek out additional relationships in order to fulfill multiple needs by different partners. In the current research we sought to assess whether partners in polyamorous relationships differ with regards to their experienced eroticism and nurturance, and whether individuals in polyamorous relationships are able to maintain higher levels of eroticism and nurturance than individuals in monogamous relationships through having multiple relationships.

\section{Theoretical Framework}

Van Anders Sexual Configuration Theory (2015) advances that eroticism, or "aspects of sexuality tied to bodily pleasure, orgasm, arousal, tantalization, and related concepts," and nurturance, or "warm loving feelings and closeness," serve fundamental roles in relationships. 
Sexual Configuration Theory proposes that individuals may pursue some intimate relationships for eroticism, others for nurturance, and still others for both of these qualities. While van Anders (2015) provides a theoretical context for the role of eroticism and nurturance in relationships, and while research related to these concepts—-such as passionate and companionate love — can help provide insight into how eroticism and nurturance may be experienced in relationships, to date it remains unclear if engaging in relationships with multiple partners results in different experiences with eroticism and nurturance. That is, do individuals who engage in polyamorous relationships and thus have multiple simultaneous partners experience higher levels of eroticism and nurturance than those who rely on one partner to meet their needs?

Passionate and Companionate Love. While the current paper seeks to assess eroticism and nurturance, the fulfilment of these needs has most often been studied in the context of love, which is frequently conceptualized as either passionate or companionate (Hatfield \& Walster, 1978). Consequently, we rely on research on passionate and companionate love to serve as a proxy for what might be found when exploring eroticism and nurturance in relationships. Passionate love is characterized as an intensely emotional state that involves longing for union with another person and strong sexual desire between partners. With companionate love, in contrast, strong sexual desire is replaced by increased intimacy (e.g., caring, understanding, attachment) that requires time to develop fully (Sprecher \& Regan, 1998). Although passionate and companionate love are not mutually exclusive, they may be more prominent at different stages of a relationship. More specifically, passionate love is most closely associated with the early stages or the "honeymoon" period of a relationship (though passion can still be experienced in the later stages, it tends to decline on average), and companionate love with the later stages (Hatfield et al., 1984; Sprecher \& Regan, 1998). 
Outsourcing Needs in Relationships. The differing time courses of passionate and companionate love are also consistent with evolutionary perspectives about the formation of adult pair bonds. Since pair bonds require time and close physical proximity to form, the characteristics of the early stage of a relationship include an intense longing for closeness with a partner (Hazan \& Diamond, 2000; Tennov, 1979). However, over time, an attachment bond is thought to form, reducing the intensity of the desire for physical proximity as the relationship becomes more predictable and familiar (Eagle, 2007). Therefore, from an evolutionary perspective, feelings of passionate love are the mechanism by which initial attraction becomes attachment, facilitating the initiation of longer-term romantic relationships. Social and evolutionary psychologists even agree on a timeframe for this shift, such that passionate love is thought to last approximately two years, plus or minus six months (Tennov, 1979), while attachment bonds typically form one and a half to three years after a relationship is initiated (Winston, 2004).

Importantly, Eagle (2007) argues the features of attachment work against erotic desire. According to Eagle, for a romantic partner to serve as an attachment figure they need to be available, familiar, and predictable. These characteristics, however, thwart feelings of sexual desire, which she argues is conversely ignited by novelty and unpredictability. If, in fact, familiarity and predictability are key features of an attachment figure and if sexual desire for a partner is diminished by these characteristics, then once an attachment bond is formed in a relationship, it is likely that sexual desire will decrease. Similar ideas are echoed by Mitchell (2002) and Perel (2007) who have independently argued that initial erotic desire — and related feelings of passion - wanes as partners impose boundaries on one-another to reduce relational insecurity, and that sexual desire can be negatively impacted by increasing closeness and 
familiarity. Clinical reports (Levine, 2003), along with qualitative (Sims \& Meana, 2010) and quantitative research (Levy, 1994) provide additional support for these arguments, such that familiarity, monotony, preoccupation with non-sexual matters, and predictability are shown to undermine erotic desire.

To the extent that passionate and companionate love are related to eroticism and nurturance, this research and theorizing may suggest differing trajectories for the experience of erotic desire and nurturance. If this is the case, like different forms of love, it may be challenging to experience high levels of eroticism and nurturance with one romantic partner at a single point in time. In fact, this problem is likely compounded by the burden of contemporary expectations about the functions of romantic relationships. Today, it is commonly assumed that committed relationships should meet many higher-order needs like happiness and personal fulfillment, while at the same time, many couples find it challenging to invest the time and energy needed to fulfill all these needs (see Finkel, Hui, Carswell, \& Larson, 2014). One solution to this problem is to alter expectations about romantic relationships and outsource needs. Indeed, it has been proposed that couples could alter their expectations about relationships; that is, rather than relying on one partner to meet both erotic and nurturant needs, individuals could outsource their needs to other relationships, diversifying their need fulfilment across multiple romantic or sexual partners (Conley, Matsick, Moors, \& Ziegler, 2017; Conley \& Moors, 2014).

In consensually non-monogamous relationships, all partners agree it is acceptable to have additional romantic or sexual partners (Conley, Ziegler, Moors, Matsick, \& Valentine, 2013). Given that consensually non-monogamy provides the opportunity to simultaneously pursue relationships, it may be possible for individuals in consensually non-monogamous relationships to concurrently experience high levels of eroticism along with nurturance through relationships 
with various partners. Thus, if relationships tend to decline in eroticism and increase in nurturance over time, it is possible that individuals in consensually non-monogamous relationships seek out secondary relationships to experience both eroticism and nurturance.

\section{Relationship Orientation}

In the current research we focus on polyamory, the practice and acceptance of having multiple emotionally-close relationships with the consent of all partners involved (Barker \& Langdridge, 2010). Polyamorous relationships are particularly useful to study in this context because unlike other popular forms of consensually non-monogamous relationship (e.g., open and swinging), partners are permitted to seek both eroticism and nurturance outside of a dyad. The most common polyamorous relationship configuration is characterized by a distinction between primary and secondary relationship partners (Balzarini et al., 2018b; Veaux, 2011; Veaux, Hardy, \& Gill, 2014). In this configuration, a primary relationship is between two partners who have been together for a longer duration, typically share a household and finances, who are married, and who have or are raising children together (if children are desired)

(Balzarini et al., 2017; 2018b; Sheff, 2013; Veaux, 2011). In such arrangements, partners beyond the primary relationship are often referred to as 'secondary' partners and consist of less ongoing commitments and a shorter relationship duration (Balzarini et al., 2017; 2018b).

Previous research has shown that meaningful differences also emerge among partners in polyamorous and monogamous relationships. For example, Mogilski and colleagues (2017) found that individuals engage in more mate retention behaviors (i.e., public signals of possession, direct guarding) and report greater satisfaction with monogamous and primary partners compared to secondary partners. Furthermore, Balzarini and colleagues (2018b) found that participants reported greater acceptance from friends and family, as well as higher 
investment, satisfaction, and commitment in relationships with monogamous or primary partners compared to secondary partners. In contrast, participants reported greater quality of alternatives, higher romantic secrecy (e.g., they hid more aspects of their relationship to others) and a greater proportion of time spent on sexual activity in their relationship with secondary partners compared to their relationships with primary partners and to reports for monogamous partners (Balzarini et al., 2018b). This research suggests that primary partners resemble monogamous partners in many ways, though secondary partners seem to diverge with proportion of time spent on sex being one of the unique features that is higher among secondary partners. In contrast to Balzarini and colleague's (2018b) findings, Mitchell and colleagues (2014) found that polyamorous individuals actually reported more sexual contact with primary partners (which could be because people tend to spend more time with primary compared to secondary partners) but greater fulfillment of sexual needs with their secondary partners compared to primary. While this research did not assess comparisons to monogamous relationships, it still provides initial evidence in support of the idea that individuals may seek out consensual extradyadic relationships in order to have diverse needs fulfilled.

Although primary-secondary relationships are the most common polyamorous arrangements (Balzarini et al., 2018b), not all people in such relationships identify with this labeling, instead, some consider multiple partners to be primary (co-primary) or no partners to be primary (non-primary; Balzarini et al., 2018b; Labriola, 2003). The only study to date to assess relationship quality among such configurations has found that even in co-primary and nonprimary relationships, there is often a partner who can be characterized as more primary, or “pseudo-primary," and another as more secondary, or "pseudo-secondary.” Despite the designated primary status, individuals in polyamorous relationships who reject primary- 
secondary status are often more inclined to live with one partner over another, and this partner is typically the individual with whom they are married and have kids. In such cases, participants report greater acceptance from friends and family, higher commitment, investment and communication for this partner (pseudo-primary), and romantic secrecy and proportion of time spent on sex for the pseudo-secondary partner. Balzarini et al. (2018b) have argued that such differences may reflect the practical allocation of relationship investments imposed by a society that is not particularly tolerant of such relationships that may occur despite motivated striving for equality across partners. As such, in co-primary and non-primary relationships, the pseudoprimary partner resembles primary partners in primary-secondary configurations and we would therefore expect to find similar patterns of eroticism and nurturance across these alternative forms of polyamorous relationships.

\section{Cross Partner Effects}

If individuals in consensually non-monogamous relationships are able to experience higher levels of eroticism and nurturance through having their needs met across partners, it is possible that the diversification of needs could influence concurrent relationships. Indeed, recent research by Muise and colleagues (2018) suggests that greater sexual need fulfillment with a primary partner was associated with greater sexual satisfaction with their secondary partner, though greater sexual need fulfilment with a secondary partner was associated with less satisfaction with a primary partner. Furthermore, while research by Mitchell and colleagues (2014) found that greater need fulfillment (in some domains) with one partner was associated with less satisfaction with the other, when need fulfillment was low with one partner, having another partner meet those needs was associated with higher satisfaction with both partners. Though when need fulfillment was lower in one relationship, need fulfillment in another 
relationship detracted from satisfaction, resulting in lower satisfaction with the first partner. This research suggests that diversifying needs across partners can have both detrimental and beneficial effects.

\section{Current Study}

Building on previous research (Balzarini et al., 2017; 2018b; Mogilski et al., 2017) assessing differences among polyamorous and monogamous partners, and drawing on Sexual Configuration Theory (van Anders, 2015), we sought to assess the extent to which eroticism and nurturance differ among polyamorous and monogamous partners. Given that primary relationships in polyamory resemble monogamous relationships and both of these relationships are characterized by greater commitment, investments, and efforts to retain a mate (Balzarini et al., 2018a; Mogilski et al., 2017), we would expect these relationships to be characterized by greater nurturance. Conversely, most evidence suggests a greater proportion of time is spent on sexual activity with secondary partners (Balzarini et al., 2017; Balzarini et al., 2018b; Balzarini, Dobson, Kohut, \& Lehmiller, 2018c; see Mitchell et al., 2014 for an exception) and that secondary partners provide greater sexual need fulfillment than primary partners (Mitchell et al., 2014) — which provides preliminary evidence that these relationships may be characterized as more erotically fulfilling. If this is the case, it would suggest that individuals in polyamorous relationships are experiencing higher levels of eroticism and nurturance than individuals in monogamous relationships through diversifying their needs. Additionally, we also sought to explore whether there are unique benefits to doing so, thus we wanted to assess whether experiencing more eroticism or nurturance with one partner in a polyamorous relationship influenced a concurrent relationship. Lastly, given that previous research has shown that monogamous and polyamorous participants present important demographics differences (see 
Balzarini et al., 2018a for a review) and because sociodemographic factors may influence eroticism and nurturance (van Anders, 2015), we further sought to assess how relationship orientation (e.g., monogamous vs polyamorous), primary status (e.g., identifying partners as primary-secondary, co-primary, and non-primary), relationship length, gender, sexual orientation, and age impacted reports of eroticism and nurturance.

\section{Study 1}

In Study 1 we sought to assess whether individuals in polyamorous relationships report different levels of eroticism and nurturance for their partners. Building on the previous research assessing differences among primary and secondary partners, we predicted that participants in polyamorous relationships would report higher nurturance (Hypothesis 1) and lower eroticism

(Hypothesis 2) with primary partners compared to secondary partners. We also sought to explore whether comparisons among partners remained when we controlled for gender, sexual orientation, age, relationship length, and primary status (Exploratory 1). Additionally, given that previous research has shown that features related to eroticism tend to decrease over time, while features related to nurturance tend to increase, we sought to explore whether relationship length was related to reports of each (Exploratory 2).

We also made a series of predictions to assess whether eroticism and nurturance impacted relationship and sexual outcomes. As eroticism is characterized by feelings of arousal, passion, lust, and sexual pleasure, we expected eroticism to be associated with greater sexual satisfaction with a relationship (Hypothesis 3). However, as nurturance is characterized by intimacy, warmth, and love, we have no reason to suspect nurturance to influence sexual satisfaction and thus a null effect was predicted (Hypothesis 4). In contrast, because eroticism and nurturance both involve 
components of either sexual or emotional intimacy, we predicted that nurturance and eroticism would be positively associated with closeness in relationships (Hypothesis 5 and 6).

While we did not advance predictions for cross-partner effects, we further sought to explore how experiencing eroticism or nurturance in one romantic relationship may be related to relationship outcomes in a concurrent relationship. Given previous research assessing need fulfillment across partner in consensually non-monogamous relationships, it is also possible that experiences of eroticism in one relationship could influence the other, and similarly for nurturance. For example, if eroticism is low in primary relationships, experiencing eroticism in a secondary could result in greater sexual satisfaction for both partners, and if nurturance is low in a secondary relationship, nurturance in a primary relationship could result in greater connection for both partners. Contrarily, if primary relationships are characterized by nurturance or sought after to meet nurturing needs, high nurturance with a secondary partner may detract from connection with a primary, and if secondary relationships are sought out to meet erotic needs, high eroticism with a primary may detract from sexual satisfaction with the secondary. As such, in addition to the pre-registered hypotheses, we sought to assess whether eroticism and nurturance with one partner influenced reports of closeness and sexual satisfaction with a concurrent partner (Exploratory 3). All of the predictions were pre-registered on the Open Science Framework prior to analyses (see: https://osf.io/s2p6f/).

\section{Method}

Participants. Participants were recruited online from Facebook and Reddit to take part in the study. Many of the places in which we posted advertisements were specifically geared toward people in polyamorous relationships (e.g., Facebook groups for polyamory discussions and reddit subgroups for polyamory), and the advertisements for recruitment solicited volunteers 
to participate in a study about polyamorous relationships. We recruited a convenience sample of 1,168 individuals who were currently in at least two concurrent relationships and identified as polyamorous, which we defined as dating multiple people with my partner(s) acknowledgement. Participants were primarily white (86.2\%), bisexual (43.3\%), females (61.0\%), who were married $(34.7 \%)$ or seriously dating $(33.5 \%)$ their partners and were in their early to mid-30's ( $M$ $=33.5, S D=9.2)$. On average, participants were in relationships with their primary partners for 7 years $(M=7.2, S D=6.9)$ and secondary partners for 2 years $(M=2.2, S D=3.6)$. Demographic information for the participants are presented in Table 1.

Procedure and Measures. Participants were informed that in order to participate in the study, they must identify as polyamorous (e.g., dating multiple people with my partner(s) acknowledgement), be at least 18 years of age, and currently be in a relationship with at least two people. Prospective participants were provided a link that re-directed them to a survey hosted on Qualtrics, an online survey program. Participants first saw a letter of information and were asked to give digital consent at the end of the letter. Study materials can be found on the Open Science Framework (see https://osf.io/fymsb/) and the measure used in the current study are explained below.

Primary Status. Primary-secondary, co-primary, and non-primary polyamorous configurations were identified by asking participants, "Do you consider your relationship with $(\mathrm{X})^{1}$ to be primary?", with response options including, "Yes, $(\mathrm{X})$ is my primary relationship", "Yes, $(\mathrm{X})$ is my primary relationship, but I also have others that are considered primary", "No, (X) is not a primary relationship", "No, I do not believe in considering one relationship to be primary", and "None of the above (please explain)." To identify primary-secondary polyamorous

\footnotetext{
${ }^{1}$ Items like this were presented to participants with their partners initials in place of the (X).
} 
configurations, those who stated that the first listed partner was primary and the second person listed was not were considered primary-secondary relationships. To be identified as being in a co-primary polyamorous configuration, participants had to indicate that both the first person listed and the second person listed were primary partners, and for no-primary polyamorous configurations, they had to indicate that they did not identify either of their partners as primary partners. Those whose responses could not be classified under one of the three relationship categories were excluded from analyses involving primary status classifications $(n=147)$.

Within primary-secondary configurations, primary relationships were easily distinguished from secondary relationships as we could rely on participants' self-reported primary status. When participants did not identify their partners as primary-secondary (co-primaries and nonprimaries), we defined pseudo-primary and pseudo-secondary relationships using a bivariate index of relationship duration and cohabitation. Specifically, participants reported relationship duration and cohabitation status for each partner separately, we then created a standardized score for both duration and cohabitation, then mean averaged them for each participant to create a single score. We then assigned the relationship with the person with the highest score the status of primary relationship and the other partner was designated as secondary for comparison purposes. $^{2}$

Eroticism Scale. The Eroticism Scale consisted of four items assessing how characteristic eroticism (e.g., my relationship with (X) is characterized by: "eroticism”, "desire and lust", “sexual excitement", and "bodily pleasure"; primary $\alpha=.97$; secondary $\alpha=.96$ ) was of one's

\footnotetext{
${ }^{2}$ It is our sincere hope that our attempt to re-classify co-primary and non-primary relationships, and our imposition of the terms "pseudo-primary" and "pseudo-secondary" partners does not upset participants who contributed to this work or the wider polyamorous and CNM communities from which they were drawn. We use this language as a means to systematically differentiate among groups in our sample and for sake of simplicity in interpreting the results.
} 
relationship. The items for eroticism were premised on van Anders' (2015) conceptualization of eroticism which incorporated elements of eroticism, desire and lust, sexual excitement, and bodily pleasure (see S2 for more information). Participants rated each item on a 7-point scale (1 $=$ Not true at all, 7 = Definitely true), and items were mean aggregated to create a composite score, with greater ratings indicating more eroticism.

Nurturance Scale. The Nurturance Scale consisted of five items assessing how characteristic nurturance (e.g., my relationship with $(\mathrm{X})$ is characterized by: "a strong sense of security", “emotional attachment", “deep commitment", "nurturance”, and "warmth and comfort"; primary $\alpha=.86$; secondary $\alpha=.91$ ) was of one's relationship. The items for nurturance were premised on van Anders' (2015) conceptualization of nurturance which tapped into security, emotional attachment, commitment, and warmth (see S2 for more information about the scale). Participants rated each item on a 7 -point scale $(1=$ Not true at all, $7=$ Definitely true $)$, and the five nurturance items were mean aggregated to create a composite score, with greater ratings indicating more nurturance.

Closeness. Closeness to one's partner was assessed with the one-item Inclusion of Other in the Self (IOS) Venn diagram (Aron, Aron, \& Smollan, 1992). This is a simple, validated, and commonly used scale to measure closeness (e.g., see Aron et al., 1992; Fraley \& Aron, 2004).

Sexual Satisfaction. Sexual satisfaction was assessed with one item with which participants reported their satisfaction with their sexual quality $(1=$ Very unhappy, $7=$ Very happy).

Data Analytic Strategy. We conducted a power analysis to ensure we had sufficient power to estimate the main effects of interest. The power analysis indicated a sample size of 175 would be needed to find a statistically significant difference assuming a medium effect size $(f=$ 
.25) with a power level of .95 (power estimated using G-Power 3.1; Faul, Erdfelder, Buchner, \& Lang, 2009). As our sample consisted of well over 350 polyamorous individuals, we decided to proceed with the analyses.

To assess whether eroticism and nurturance differed among primary and secondary partners, we performed paired sample $t$-tests comparing polyamorous participants report of eroticism and nurturance between primary and secondary partners. The effect size, or Cohen's $d$, is presented with the results for each comparison. The effect sizes can be interpreted based on Cohen's (1988) guidelines, which suggests a value of 0.2 is a small effect, 0.5 is a medium effect, while 0.8 or above is a large effect. Using multivariable regressions, we also assessed comparisons between primary and secondary partners controlling for sexual orientation, gender, and relationship length.

We further sought to examine predictions regarding the association between eroticism and nurturance and reports of closeness and sexual satisfaction (e.g., whether eroticism with a primary was associated with closeness or sexual satisfaction with this partner), and the exploratory questions on cross-partner interactions (e.g., whether eroticism with a primary partner was associated with reports of closeness or sexual satisfaction with a secondary). We analyzed the data using multilevel modeling based on a modified actor partner interdependence model (see Muise et al., 2018 for a similar approach). Participants' reports about both their primary and secondary partners were entered simultaneously into the model. In the first model, we entered primary partner eroticism and nurturance and secondary partner eroticism and nurturance as predictors of closeness. In the second model, we entered primary partner eroticism and nurturance and secondary partner eroticism and nurturance as predictors of sexual satisfaction. Because eroticism and nurturance are not mutually exclusive, we tested the effects 
of eroticism and nurturance simultaneously, and we included reports for primary and secondary partners to examine cross-relationship effects of eroticism and nurturance simultaneously while accounting for the same relationship effects. In subsequent analyses, we tested whether primary status (e.g., whether partners were identified as primary-secondary, co-primary, or non-primary) influenced the results.

\section{Results}

Tests of Key Predictions. As predicted, participants rated their relationship with primary partners as characterized by greater nurturance than their relationship with secondary partners $(\mathrm{P} 1: M=6.23, S D=1.05 ; \mathrm{P} 2: M=5.05, S D=1.51, t(679)=17.76, p<.001, d=0.68)$, while relationships with secondary partners were characterized by greater eroticism $(\mathrm{P} 2: M=5.67, S D$ $=1.64)$ than their primary relationships $(\mathrm{P} 1: M=4.84, S D=1.91 ; t(679)=-8.64, p<.001, d=$ 0.26; see Figure 1). When we adjusted for demographic factors of relationship length, sexual orientation, and gender identity, this difference remained significant, such that secondary partners were more likely to be rated higher in eroticism $(b=0.84,95 \% \mathrm{CI}[.67,1.03], t(1428)=$ 9.16, $p<.001)$, but lower in nurturance compared to primary partners $(b=-1.13,95 \%$ CI $[-1.26$, -.99], $t(1428)=16.45, p<.001)$.

\section{Tests of Exploratory Analyses Assessing Eroticism and Nurturance by Relationship}

Length. We further sought to assess whether eroticism and nurturance were associated with relationship length. Results suggest that eroticism was negatively associated with relationship length, such that it decreased with increases in relationship length among both primary $(b=-$ $0.05[-0.09,-0.04], p<.001)$ and secondary partners $(b=-0.06[-0.09,-0.03], p<.001)$, while levels of nurturance were positively associated with longer relationship lengths for both primary $(b=0.03[0.02,0.04], p<.001)$ and secondary partners $(b=0.07[0.04,0.09], p<.001)$. Though we will note that as evident in the reported magnitude of these associations, these 
increases/decreases for every one-year increase in relationship length were quite small. When we assessed these associations while controlling for relationships length, age, sexual orientation, and gender, similar results were found (data not shown, available on the OSF: https://osf.io/z6bvs/).

\section{Tests of Predicted Partner Effects and Exploratory Analyses for Closeness and Sexual}

Satisfaction Across Relationships. People who reported more nurturance in their primary relationship reported greater closeness in their relationship with their primary partner $(b=0.58$, $95 \%$ CI $[.48, .68], t(675)=11.73, p<.001)$ and those who reported greater nurturance with their secondary partner reported greater closeness in their relationship with their secondary partner $(b$ $=0.55,95 \%$ CI $[.48, .63], t(675)=15.19, p<.001)$. However, participants who reported more nurturance in their primary relationship did not report feeling closer to their secondary partner $(p$ $=.769$ ), but the reverse cross-relationship association - between secondary partner nurturance and primary partner relationship closeness - was marginally significant and suggested a trend where higher nurturance from a secondary partner was associated with less closeness in a primary relationship $(b=-0.06,95 \% \mathrm{CI}[-.13, .01], t(675)=-1.81, p=.070)$. When we assessed these effects controlling for primary status (e.g., whether participants considered their partner to be primary-secondary, co-primary, or non-primary), this cross-partner effect became nonsignificant $(p=.523)$, all other effects for nurturance remained.

Unlike the effects for nurturance, reports of eroticism with primary partners were not associated with ratings of closeness with their primary partner $(p=.136)$, though people who reported more eroticism with their secondary partner reported greater closeness in their relationship with their secondary partner $(b=0.11,95 \%$ CI $[.41, .68], t(675)=3.11, p=.002)$. In addition, participants who reported more eroticism in their primary relationship reported feeling less close to their partner in their secondary relationship $(b=-0.08,95 \% \mathrm{CI}[-.14,-.02], t(675)=$ 
$-2.71, p=.007)$, but participants who reported more eroticism in their secondary relationship reported feeling closer to their partner in their primary relationship $(b=0.07,95 \% \mathrm{CI}[.00, .14]$, $t(675)=2.04, p=.042)$. When we assessed these effects controlling for primary status, this cross-partner effect for eroticism with a secondary partner and closeness with a primary became marginally significant $(p=.066)$, though all other effects for eroticism remained.

Nurturance was not related to reports of sexual satisfaction with primary $(p=.208)$ or secondary partners $(p=.615)$. Furthermore, reports of secondary partner nurturance was not associated with sexual satisfaction with primary partners $(p=.406)$, and reports of nurturance with primary partners was not associated with reports of sexual satisfaction with secondary partners $(p=.910)$. When we assessed these effects controlling for primary status, the effect of nurturance with primary partners with satisfaction of sex with a primary partner became significant $(b=0.12,95 \%$ CI $[.00, .24], t(608.15)=1.98, p=.048)$, though all other effects remained non-significant.

People who reported more eroticism in their primary relationship reported greater sexual satisfaction in their relationship with their primary partner $(b=0.58,95 \%$ CI $[.52, .64], t(630.42)$ $=18.89, p<.001)$. Similarly those who reported greater eroticism with their secondary partner reported greater sexual satisfaction with their secondary partner $(b=0.56,95 \%$ CI [.48, .64], $t(457.36)=14.34, p<.001)$. Next, we assessed cross partner effects, and people who reported greater eroticism with their secondary partner reported less sexual satisfaction in their relationship with their primary partner $(b=-0.12,95 \%$ CI $[-.19,-.05], t(626.91)=-3.41, p=$ .001). Likewise, participants who reported more eroticism in their primary relationship reported (marginally) less sexual satisfaction with their secondary partner $(b=-0.06,95 \%$ CI [-.12, .00], $t(456.23)=-1.93, p=.054)$. When we assessed these effects controlling for primary status, this 
cross-partner effect became non-significant $(p=.091)$, though all other effects for eroticism remained.

\section{Study 2}

In Study 2, we aimed to test whether eroticism and nurturance differed between partners in polyamorous and monogamous relationships. While Study 1 suggests that individuals in polyamorous relationships experience greater eroticism in their relationship with their secondary partner, and yet greater nurturance in their relationship with their primary partner, we further sought to assess whether polyamorous relationships may afford individuals the opportunity to experience higher levels of eroticism and nurturance simultaneously compared to relationships with a monogamous partner. To assess this claim, we acquired a monogamous sample in Study 2 and used the polyamorous sample from Study 1 to test a series of hypotheses. More specifically, previous research has shown that monogamous partners resemble reports for polyamorous primary partners for commitment, satisfaction, mate-retention, and other relationship relevant outcomes (Balzarini et al., 2018b; Mogilski et al., 2017), while polyamorous secondary partners tend to be rated lower on these traits but have higher sexual frequency compared to monogamous and primary partners (e.g., Balzarini et al., 2018b; Balzarini et al., 2018c; Mogilski et al., 2017). Given this previous research and the findings from Study 1, we predicted that monogamous participants would report higher nurturance (Hypothesis 7) and lower eroticism (Hypothesis 8) compared to polyamorous participants reports of their secondary partners, though no differences in nurturance (Hypothesis 9) and eroticism (Hypothesis 10) were expected for monogamous partners compared to primary partners. We further expected relationship length to be associated with eroticism and nurturance, such that relationship length would be negatively associated with eroticism and yet positively associated with nurturance (Hypothesis 11), consistent with Study 
1's findings. We also sought to explore whether experiences of eroticism and nurturance differ with regards to gender, sexual orientation, age, relationship length, and primary status (Exploratory 4). Finally, consistent with the rationale outlined in Study 1, we expected eroticism to be associated with greater sexual satisfaction with a relationship among monogamous participants (Hypothesis 12), though a null effect was predicted for nurturance (Hypothesis 13). In contrast, we predicted that nurturance and eroticism would be positively associated with closeness in relationships with monogamous partners (Hypothesis 14 and 15). All of the predictions for Study 2 were pre-registered on the OSF prior to analyses (see: https://osf.io/twy6x/).

\section{Method}

Participants. Participants were recruited from Qualtrics panel, an online crowdsourcing platform. A convenience sample of 2,183 individuals who were currently in an exclusive monogamous relationship were recruited. Participants were primarily white (defined as Western / Eastern European; $66.5 \%)$, heterosexual (92.2\%), females (68.5\%), who were married (82.5\%) to their partners and were 45 years old on average $(M=45.39, S D=15.16)$. On average, participants were in relationships with their partner for 17 years $(M=17.34, S D=14.32)$. For more information about the demographics of the participants, see Table 1.

Procedure and Measures. Participants were told that the purpose of this study was to better understand experiences in romantic relationships. Participants were first asked to fill out a questionnaire that assessed demographic information. Participants were then asked complete a series of questionnaires that included the nurturance and eroticism scale as well as the passionate and companionate love scale. Participants then took part in an informational intervention that was conducted for the purposes of another study (see: https://osf.io/9thb4/). One week later, 
participants were invited to take a follow-up survey. The scale of interest was not included in the Part 2 portion of the survey, and as such, we will be focusing on Part 1 data in the current paper.

Study 2 included the same measures for eroticism $(\alpha=.96)$, nurturance $(\alpha=.90)$, and closeness (Aron et al., 1992) that were used in Study 1, though sexual satisfaction was measured with the Global Measure of Sexual Satisfaction (GMSEX; Lawrance \& Byers, 1998).

Participants were asked to indicate on 7-point bipolar scales which best describes their current sexual relationship: unsatisfying-satisfying, unpleasant-pleasant, and good-bad. Items were mean aggregated with higher scores indicating higher sexual satisfaction $(\alpha=.97)$.

Data Analytic Strategy. We conducted a power analysis to ensure we had sufficient power to estimate the main effects of interest. The power analysis indicated a sample size of 1736 would be needed to find a statistically significant difference assuming a small effect size $(d$ $=.20)$, with unequal allocation $(\mathrm{N} 3 / \mathrm{N} 1=3$; to resemble the ratio of eligible participants in the dataset). with a power level of .95 (power estimated using G-Power 3.1; Faul, Erdfelder, Buchner, \& Lang, 2009). As our sample consisted of well over 1736 monogamous and polyamorous individuals, we decided to proceed with the analyses.

To test our hypotheses comparing polyamorous and monogamous relationships, a series of two sample independent $t$-tests were performed to compare the mean scores of eroticism and nurturance for reports of partners in monogamous relationships with the reports for polyamorous individuals primary and secondary partners. To assess the effects of relationship length and address our exploratory questions regarding sociodemographic variables, we used a series of univariate regressions to examine the association between age, sexual orientation, relationship length, and gender with comparisons of eroticism and nurturance. As an exploratory analysis, we also conducted a one-way ANOVA to explore the differences in eroticism and nurturance 
between monogamous partners and partners in the various polyamorous configurations (e.g., partners in primary-secondary, non-primary, co-primary relationships). We then used Tukey's test to compare the different pairwise comparisons of monogamous partners to primary/pseudoprimary partners and secondary/pseudo-secondary partners in the varying configurations. Lastly, to assess whether eroticism and nurturance was associated with sexual satisfaction or closeness in monogamous relationships, we conducted a series of regression analyses with erotism and nurturance predicting sexual satisfaction, and then predicting closeness.

\section{Results}

Primary Analyses. Compared to monogamous partners, individuals in polyamorous relationships rated their primary partners higher in nurturance $(\mathrm{P} 1: M=6.18, S D=1.07 ; \mathrm{PM}: M$ $=5.85, S D=1.32 ; t(2924)=6.18, p<.001, d=0.26)$, but lower in eroticism $(\mathrm{P} 1: M=4.83, S D$ $=1.89 ; \mathrm{PM}: M=5.16, S D=1.60 ; t(2924)=-4.63, p<.001, d=0.19)$. On the other hand, secondary partners were rated lower in nurturance than monogamous partners (P2: $M=5.05, S D$ $=1.51 ; \mathrm{PM}: M=5.85, S D=1.32 ; t(2846)=-13.25, p<.001, d=0.58)$, but higher in eroticism $(\mathrm{P} 2: M=5.67, S D=1.64 ; \mathrm{PM}: M=5.17, S D=1.60 ; t(2846)=7.27, p<.001, d=0.32)$. As an exploratory analysis, we sought to assess whether the results remained when we controlled for sociodemographic factors. Comparisons for eroticism and nurturance among monogamous partners and polyamorous primary and secondary partners held when we controlled for gender, sexual orientation, relationship length, and age (see Table 5). However, while nurturance among primary partners was higher than reports for monogamous partners, this was only true among polyamorists who identify their partners as primary-secondary and co-primary, whereas polyamorists who did not identify either partner as primary (non-primary) reported similar rating of nurturance for their pseudo-primary partner compared to monogamous partners (see Table 4-5 and Figure 1 for mean ratings). On the other hand, while on average, polyamorous secondary 
partners were characterized by less nurturance compared to monogamous partners, this was true only for secondary/pseudo-secondary partners in primary-secondary and non-primary configurations, whereas individuals who considered both of their partners to be primary (i.e., coprimary) reported similar levels of nurturance for their pseudo-secondary partner compared to monogamous partners. When we assessed comparisons for eroticism, we found across all polyamorous configurations, reports for eroticism were lower for polyamorous primary/pseudoprimary partners than monogamists, while reports for eroticism were higher among secondary and pseudo-secondary partners than monogamous partners (see Table 4 and Figure 1). Most of these effects held when we controlled for gender identity, sexual orientation, and relationship length (see Table 5).

Assessing Eroticism and Nurturance by Relationship Length. Relationship length (expressed as increments of 10 years) was negatively associated with eroticism $(b=-0.23,95 \%$ CI $[-0.28,-0.19], p<.001)$, and nurturance $(b=-0.08,95 \%$ CI $[-0.12,-0.04], p<.001)$ for partner in monogamous relationships, though the magnitude of this effect was small. When we controlled for participant's age, relationship length was no longer associated with nurturance among the monogamous sample $(p=.68)$.

Tests of Predicted Associations with Relationship Quality. Individuals in monogamous relationships who reported more nurturance in their relationship with their partner reported greater closeness with their partner $(b=0.45, t(2164)=34.89, p<.001)$, and greater sexual satisfaction $(b=0.50, t(2166)=38.13, p<.001)$. Similarly, people who reported more eroticism in their relationship reported greater closeness in their relationship $(b=0.52, t(2164)=33.60, p$ $<.001)$, and greater sexual satisfaction $(b=0.76, t(2166)=60.61, p<.001)$. These results 
remained significant when we controlled for gender, sexual orientation, and relationship length (see OSF: https://osf.io/c7yjw/).

\section{Discussion}

According to Sexual Configuration Theory (van Anders, 2015), two central components of relationships are their ability to provide people with eroticism and nurturance. While previous research has assessed similar themes, such as passionate and companionate love, there has yet to be research examining eroticism and nurturance empirically. The current research sought to investigate the relationship between eroticism and nurturance among people in polyamorous and monogamous relationships and whether engaging in multiple relationships simultaneously can afford individuals higher levels of both. Results suggest that people in polyamorous relationships experience greater nurturance with primary partners (compared to secondary and monogamous partners) and greater eroticism with secondary partners (compared to primary and monogamous partners). Moreover, consistent with research suggesting that processes related to eroticism and nurturance are impacted by relationship length, we found that among the polyamorous sample, eroticism was negatively associated with relationship length, while levels of nurturance were positively associated with relationship length. Among the monogamous sample, however, both eroticism and nurturance were negatively associated with relationship length, and effects for nurturance and relationship length disappeared when we controlled for age. When decreases in nurturance did occur, the decline was very small, translating to a 0.1 change in the nurturance with a 10-year increase in relationship length- thus, while this finding is contrary to what might be expected for nurturance, the finding should be interpreted with caution given the small effect size. 
Differences in eroticism and nurturance between primary and secondary partners in polyamorous relationships are consistent with previous research showing that individuals report greater emotional support, closeness, security, interdependence, and companionate love with primary partners compared to secondary partners (Balzarini et al., 2017; Balzarini et al., 2018b; Jiang, 2017; Mitchell et al., 2014). Given the previous research, it would make sense that primary relationships are characterized by greater intimacy, love, and warmth, which are components of nurturance. In contrast, eroticism was higher in secondary relationships, which is consistent with previous research suggesting that relationships with secondary partners typically involve a greater proportion of time spent having sex (Balzarini et al., 2017; Balzarini et al., 2018b; Balzarini et al., 2018c; for an exception see Mitchell et al., 2014; Mogilski et al., 2017) and greater sexual need fulfillment (Mitchell et al., 2014).

Comparisons between polyamorous and monogamous relationships, however, were less aligned with our predictions. Although secondary relationships were characterized by greater eroticism than monogamous relationships, inconsistent with previous research showing that monogamous relationships resemble primary relationships on various relationship outcomes (Balzarini et al., 2018b; Mogilski et al., 2017), this research also indicated that primary relationships were characterized by greater nurturance then monogamous relationships. Despite these surprising results, taken together, these findings support the view that individuals in polyamorous relationships maintained higher levels of eroticism and nurturance through their concurrent partners than is typical of individuals in monogamous relationships.

The findings concerning higher than expected experience of nurturance from primary partners compared to monogamous partners deserves further attention. One possibility is that these results may reflect the strong foundation necessary to maintain a primary relationship in a 
consensually non-monogamous context. That is, it is likely that experiencing security, a deep emotional attachment, warmth, and comfort- all aspects of nurturance- may contribute to maintaining commitment between primaries in long-term polyamorous relationships and may afford partners the ability to be attuned to each other's needs and comfortable with having others fulfill some of those needs. Alternatively, it is also possible that these findings reflect differing preferences for need fulfillment, such that polyamorous individuals are more willing to experiment with alternative relationship arrangement to maximize the fulfilment of erotic and nurturing needs than monogamous individuals. Although these ideas are not tested, future research could explore whether nurturance with primary partners serves to promote relationship stability for primary partners within polyamorous relationships affording the safety and security to pursue secondary relationships, and should further explore whether people in polyamorous and monogamous relationships express different preferences for the fulfilment of eroticism and nurturance in relationships.

The current research also suggests that for monogamous partners, eroticism and nurturance were positively associated with reports of sexual satisfaction and closeness, while for polyamorous participants, eroticism was positively associated with sexual satisfaction and closeness (though only for secondary partners), while nurturance was positively associated with closeness. These findings help elucidate previously documented differences between monogamous partners and polyamorous primary and secondary partners, such that differences in commitment processes, mate-retention, sexual need fulfilment, and sexual frequency (e.g., Balzarini et al., 2017; 2018b; 2019c; Mitchell et al., 2014; Mogilski et al., 2017; Muise et al., 2018) may be an artifact of different partners meeting different roles or being pursued to meet 
different needs. In exploratory analyses we assessed whether eroticism or nurturance in a polyamorous relationship predicted closeness or sexual satisfaction in a concurrent relationship.

Our exploratory results suggest that reports of nurturance and eroticism with one partner were in some instances associated with sexual satisfaction and closeness with the concurrent partner, though the directions of the effects were largely negative or null. More specifically, the only positive effect to emerge indicated that eroticism with a secondary partner was associated with more closeness with a primary partner. In contrast, various negative cross-partner effects emerged, such that greater eroticism with a primary partner was associated with less closeness and sexual satisfaction with a secondary, while greater eroticism with a secondary partner was associated with less sexual satisfaction with a primary partner. Such results provide little evidence for the claim that diversifying needs across partners may benefit relationships, as has been argued by Finkel and colleagues (2014) and Conley and colleagues (2017, 2014), though they are somewhat consistent with some previous research that documents similarly small trends (Mitchell et al., 2014; Muise et al., 2018). Importantly, these results need to be interpreted with caution given that the exploratory nature of the analyses and magnitude of the effects. Thus, future research is needed to confirm the effects of eroticism and nurturance on concurrent relationships. Such efforts could further explore with whom the cross-partner effects are strongest, and in what instances cross-partner effects benefit versus detriment relationship quality, and beyond the relationship, whether diversifying need fulfillment of eroticism and nurturance benefits the individual (e.g., do individuals who have more needs met across partners report higher well-being or life satisfaction?).

\section{Implications}

These findings have broad research implications for the study of romantic relationships. 
The belief that monogamy is superior to other relationship orientations is a fundamental and often unquestioned assumption underlying contemporary theories of the development of romantic relationships and intimacy (Conley et al., 2017; Moors \& Schechinger, 2014), and the current findings suggest that it is valuable to consider how consensually non-monogamous relationships can inform existing perspectives of relationship quality. Conley and colleagues $(2014,2017)$ argue that monogamous relationships can be improved by outsourcing unmet needs to other non-sexual relationships. For many people, it may be unrealistic to expect one's romantic partner to meet their needs for eroticism and nurturance simultaneously. While consensually non-monogamous relationships, like polyamory, can afford the opportunity to have these needs met simultaneously through different romantic partners, monogamous individuals could also choose to have unmet nurturance needs met by friends, family members, and so forth, reducing their reliance on their partner; and they could also consider, with the knowledge and consent of their partner, outsourcing needs through use of pornography, for example, to fulfill unmet erotic needs.

One key empirical question that the current research cannot address, however, is whether experiencing eroticism and nurturance from non-romantic partners in the face of low levels of eroticism and nurturance in a relationship, can compensate for unsatisfactory levels in one's relationship(s). Relevant data are limited but suggest that support and sexual gratification from a romantic partner may be different from that provided by outside sources, and that there may be unique benefits to having erotic and nurturing needs met by a romantic partner. For example, Brown and Harris (1978) found that a confiding relationship with a parent, sister, or friend did not compensate for a lack of a confiding relationship with a partner. Additionally, other research has shown that there are times when a partner's use of sexually explicit materials can negatively 
impact a romantic relationship in a variety of domains, including feeling a sense of decreased intimacy and self-esteem (see Bergner \& Bridges, 2002), and that in general, solitary use of sexually explicit materials among males (i.e., consuming pornography when a partner does not) is associated with negative outcomes in romantic relationships (Wright, Tokunaga, Kraus, \& Klann, 2017). Thus, options to outsource unmet erotic needs in a monogamous relationship may come with some complexities, including limited options to outsource erotic needs and potentially negative effects on relationships.

There are reasons, however, to remain critical of this position. With respect to pornography use, for instance, positive effects on relationship functioning have also been identified (Kohut, Fisher, \& Campbell, 2017), and the negative associations between pornography use and relationship functioning appear to be limited to instances where partners differ in their interest in such materials (Kohut, Balzarini, Fisher, \& Campbell, 2018; Kohut et al., in prep). Although empirical evidence is scant at the moment, the determining factor in such cases may be the extent that individuals approve of and consent to their partners' use of such materials or to outsourcing needs more generally; much like arrangements in consensually nonmonogamous relationships.

\section{Limitations and Future Directions}

Despite the strengths, there are some features of the sample and methods that may limit the interpretation and impact of our findings. First, the current research used a convenience sample of polyamorous and monogamous participants who self-selected to participate in this study; therefore, the study may be limited in generalizability. Future research should assess eroticism and nurturance among a representative sample and include other relationship orientations (e.g., swingers, open relationships). Furthermore, the current research was cross- 
sectional and correlational in nature and thus the nature of this data does not allow us to answer questions about causality or directionality. While we have demonstrated that eroticism and nurturance differ between monogamous and polyamorous relationships, it is still important to establish how eroticism and nurturance and eroticism develop and change over time within these relationships.

\section{Concluding Remarks}

The current research provides the first empirical test of differences between eroticism and nurturance among partners in polyamorous and monogamous relationships. The findings suggest that polyamory may provide a unique opportunity for individuals to experience both eroticism and nurturance simultaneously, as people in polyamorous relationships experience greater nurturance with primary partners (compared to secondary and monogamous partners) and greater eroticism with secondary partners (compared to primary and monogamous partners).

Furthermore, results suggest experiences of eroticism and nurturance are associated with closeness and sexual satisfaction, and in some instance, experiences of eroticism and nurturance in polyamorous relationships influence reports of closeness and satisfaction with concurrent partners. Future research should assess the downstream consequences of partners meeting different roles and assess whether there are personal benefits (e.g., greater life satisfaction, personal well-being) of diversified fulfillment of erotic and nurturant needs. 


\section{References}

Acker, M., \& Davis, M. H. (1992). Intimacy, passion, and commitment in adult romantic relationships: A test of the Triangular Theory of Love. Journal of Social and Personal Relationships, 9, 21-50.

Aron, A., Aron, E., \& Smollen, D. (1992). Inclusion of other in the self scale and the structure of interpersonal closeness. Journal of Personality and Social Psychology, 63, 596-612.

Appel, I., \& Shmuel, S. (2015). The role of romantic attraction and conflict resolution in predicting shorter and longer relationship maintenance among adolescents. Archives of Sexual Behavior, 44, 777-782.

Balzarini, R. N., Campbell, L., Kohut, T., Holmes, B. M., Lehmiller, J. J., Harman, J. J., \& Atkins, N. (2017). Perceptions of primary and secondary relationships in polyamory. PLoS ONE, 12, 1-20.

Balzarini, R. N., Dharma, C., Kohut, T., Campbell, L., Holmes, B. M., Lehmiller, J. J., \& Harman, J. J. (2018a). Demographic comparison of American individuals in polyamorous and monogamous relationships. Journal of Sex Research. Advanced online publication.

Balzarini, R. N., Dharma, C., Kohut, T., Campbell, C., Lehmiller, J. J., Harman, J. J., \& Holmes, B. M. (2018b). Comparing relationship quality across different types of romantic partners in polyamorous and monogamous relationships, under review.

Balzarini, R. N., Dobson, K., Kohut, T., \& Lehmiller, J. J. (2018c). The role of relationship acceptance and romantic secrecy on commitment processes and the proportion of time spent on sex, under review.

Barker, M., \& Langdridge, D. (2010). Whatever happened to non-monogamies? Critical reflections on recent research and theory. Sexualities, 13, 748-772. 
Bentler, P. (1990). Comparative fit indexes in structural models. Psychological Bulletin, 107, 238246.

Berzon, B. (1988) Permanent partners: Building gay and lesbian relationships that last. New York, NY: EP.

Blumstein, P. W., \& Schwartz, P. (1983). American couples. New York, NY: Morrow.

Brown, G. W., \& Harris, T. (1978). Social origins of depression. New York, NY: Free Press

Browne, M. W., \& Cudeck, R. (1989). Single sample cross-validation indices for covariance structures. Multivariate Behavioral Research, 24, 445-455.

Call, V., Sprecher, S., \& Schwartz, P. (1995). The incidence and frequency of marital sex in a national sample. Journal of Marriage and the Family, 57, 639-650.

Cohen, J. (1988). Statistical power analysis for the behavioral sciences (2nd ed.). Hillsdale, NJ: Erlbaum.

Conley, T. D., Matsick., J., Moors., A. C., \& Ziegler, A. (2017). Investigation of consensually nonmonogamous relationships: Theories, methods, and new directions. Perspectives on Psychological Science, 12, 205-232.

Conley, T. D., \& Moors, A. C. (2014). More oxygen please! How polyamorous relationship strategies might oxygenate marriage. Psychological Inquiry, 25, 56-63.

Conley, T. D., Ziegler, A., Moors, A. C., Matsick, J. L., \& Valentine, B. (2013). A critical examination of popular assumptions about the benefits and outcomes of monogamous relationships. Personality and Social Psychology Review, 17, 124-141.

Coombs, R. H. (1991). Marital status and personal well-being: A literature review. Family Relations, 40, 97-102.

Eagle, M. (2007). Attachment and sexuality. In D. Diamond, S. J. Blatt \& J. D. 
Lichtenberg (Eds.), Attachment \& Sexuality (pp. 27-78). New York, NY: Taylor \& Francis.

Faul, F., Erdfelder, E., Buchner, A., \& Lang, A. G. (2009). Statistical power analyses using G* Power 3.1: Tests for correlation and regression analyses. Behavior Research Methods, 41, $1149-1160$.

Finkel, E. J., Hui, C. M., Carswell, K. L., \& Larson, G. M. (2014). The suffocation of marriage: Climbing Mount Maslow without enough oxygen. Psychological Inquiry, 25, 1-41.

Fraley, B., \& Aron, A. 2004. The effect of a shared humorous experience on closeness in initial encounters. Personal Relationships, 11, 61-78.

Hatfield, E., Traupmann, J., \& Sprecher, S. (1984). Older women's perceptions of their intimate relationships. Journal of Social and Clinical_Psychology, 2, 108-124.

Hatfield, E., \& Walster, G. W. (1978). A new look at love. Chicago, IL: AddisonWesley.

Hazan, C., \& Diamond, L. M. (2000). The place of attachment in human mating. Review of General Psychology, 4, 186-204.

Hazan, C., \& Shaver, P. R. (1994). Attachment theory as an organizational framework for research on close relationships. Psychological Inquiry, 5, 1-22.

Henderson-King, D. H., \& Veroff, J. (1994). Sexual satisfaction and marital well-being in the first years of marriage. Journal of Social and Personal Relationships, 11, 509-534.

Holt-Lunstad, J., Smith, T. B., \& Layton, J. B. (2010). Social relationships and mortality risk: A meta-analytic review. PLoS Medicine, 7, e1000316.

Hu, L. T, \& Bentler, P. M. (1999). Cutoff criteria for fit indexes in covariance structure analysis: Conventional criteria versus new alternatives. Structural Equation Modeling, 6, 1-55. 
Jiang, V. (2017). Different types of love in polyamory: Between primary and secondary (Unpublished undergraduate thesis). Western University, London, ON.

Jordan, K. M. \& Deluty, R. H. (2000). Social support, coming out, and relationship satisfaction in lesbian couples. Journal of Lesbian Studies, 4, 145-164.

Joreskog, K. G., \& Sorbom, D. (1984). LISREL 6: User's guide. Mooresville, IN: Scientific Software International.

Kaats, G. R., \& Davis, K. E. (1971). Effects of volunteer biases in studies of sexual behavior and attitudes. Journal of Sex Research, 7, 26-34.

Kinsey, A. C., Pomeroy, W. P., \& Martin, C. E. (1948). Sexual behavior in the human male. Philadelphia, PA: Saunders.

Kinsey, A. C., Pomeroy, W. P., Martin, C. E., \& Gebhard, P. (1953). Sexual behavior in the human female. Philadelphia, PA: Saunders.

Klesse, C. (2006). Polyamory and its 'others': Contesting the terms of non-monogamy. Sexualities, 9, 565-583.

Kline, R. B. (2011). Convergence of structural equation modeling and multilevel modeling. na.

Kohut, T., Balzarini, R. N., Fisher, W. A., \& Campbell, L. (2018). Pornography’s associations with open sexual communication and relationship closeness vary as a function of dyadic patterns of pornography use within heterosexual relationships. Journal of Social and Personal Relationships, 35, 655-676.

Kohut, T., Balzarini, R. N., Dobson, K., Rogge, R., Mcnulty, J., Fisher, B. A., Shaw, A., \& Campbell, L. (in prep). Pornography's associations with sexual and relationship satisfaction vary as a function of dyadic patterns of pornography use and perceptions of partner's use. 
Kohut, T., Fisher, W. A., \& Campbell, L. (2017). Perceived effects of pornography on the couple relationship: Initial findings of open-ended, participant-informed,"bottom-up" research. Archives of Sexual Behavior, 46, 585-602.

Labriola, K. (2003). Models of open relationships. Retrieved from http://www.cat-anddragon.com/stef/poly/Labriola/open.html.

Laumann, E. O., Gagnon, J. H., Michael, R. T., \& Michaels, S. (1994). The social organization of sexuality: Sexual practices in the United States. Chicago, IL: University of Chicago Press.

Lehmiller, J. J. (2009). Secret romantic relationships: Consequences for personal and relational well-being. Personality and Social Psychology Bulletin, 35, 1452-1466.

Lehmiller, J. J., \& Agnew, C. R. (2006). Marginalized relationships: The impact of social disapproval on romantic relationship commitment. Personality and Social Psychology Bulletin, 32, 40-51.

Levine, S. B. (2003). The nature of sexual desire: A clinician's perspective. Archives of Sexual Behavior, 32, $279-285$.

Levy, J. (1994). Sex and sexuality in later life stages. In A. S. Rossi (Ed.), Sexuality across the life course (pp. 287-309). Chicago, IL: University of Chicago Press.

Lillard, L. A., \& Waite, L. J. (1995). 'Til death do us part: Marital disruption and mortality. American Journal of Sociology, 100, 1131-1156.

MacKinnon, D. P., Krull, J. L., \& Lockwood, C. M. (2000). Equivalence of the mediation, confounding and suppression effect. Prevention Science, 1, 173-181.

MacNeil, S., \& Byers, E. S. (2009). Role of sexual self-disclosure in the sexual satisfaction of long-term heterosexual couples. Journal of Sex Research, 46, 3-14. 
Mitchell, M., Bartholomew, K., \& Cobb, R. (2014). Need fulfillment in polyamorous relationships. Journal of Sex Research, 51, 329-339.

Mitchell, S. A. (2002). Can love last? New York, NY: Norton.

Mogilski, J. K., Memering, S. L., Welling, L. L., \& Shackelford, T. K. (2017). Monogamy versus consensual non-monogamy: Alternative approaches to pursuing a strategically pluralistic mating strategy. Archives of Sexual Behavior, 46, 407-417.

Moors, A. C., \& Schechinger, H. (2014). Understanding sexuality: Implications of Rubin for relationship research and clinical practice. Sexual and Relationship Therapy, 29, 476-482.

Morton, H., \& Gorzalka, B. B. (2015). Role of partner novelty in sexual functioning: a review. Journal of Sex \& Marital Therapy, 41, 593-609.

Muise, A., Laughton, A., Moors, A. C., \& Impett, E. A. (2018). Sexual need fulfillment and satisfaction in consensually nonmonogamous relationships. Journal of Social and Personal Relationships. Advanced online publication.

Murray, S. H., \& Milhausen, R. R. (2012). Sexual desire and relationship duration in young men and women. Journal of Sex \& Marital Therapy, 38, 28-40.

Murray, S. L., Holmes, J. G., \& Griffin, D. W. (2000). Self-esteem and the quest for felt security: How perceived regard regulates attachment processes. Journal of Personality and Social Psychology, 78, 478-498.

Murray, S. L. (2005). Regulating the risks of closeness: A relationship-specific sense of felt security. Current Directions in Psychological Science, 14, 74-78.

Penke, L., \& Asendorpf, J. B. (2008). Beyond global sociosexual orientations: A more differentiated look at sociosexuality and its effects on courtship and romantic relationships. Journal of Personality and Social Psychology, 95, 1113-1135.

Perel, E. (2007). Mating in captivity: Unlocking erotic intelligence. New York, NY: HarperCollins. 
Putzke, J. D., Elliott, T. R., \& Richards, J. S. (2001). Marital status and adjustment 1 year postspinal-cord-injury. Journal of Clinical Psychology in Medical Settings, 8, 101-107.

Reis, H. T., \& Shaver, P. (1988). Intimacy as an interpersonal process. In S. Duck \& D. F. Hay (Eds.), Handbook of personal relationships: Theory, research and interventions (pp. 367389). Oxford, EN: Wiley.

Ritchie, A., \& Barker, M. (2006). “There aren't words for what we do or how we feel so we have to make them up": Constructing polyamorous languages in a culture of compulsory monogamy. Sexualities, 9, 584-601.

Rhemtulla, M., Brosseau-Liard, P. É., \& Savalei, V. (2012). When can categorical variables be treated as continuous? A comparison of robust continuous and categorical SEM estimation methods under suboptimal conditions. Psychological methods, 17, 354-373.

Rosseel, Y. (2010). Lavaan: An R package for structural equation modeling and more. Version 0.31. Retrieved from http://cran.r-project.org/web/packages/lavaan/

Rusbult, C. E. (1980). Commitment and satisfaction in romantic associations: A test of the investment model. Journal of Experimental Social Psychology, 16, 172-186.

Rusbult, C. E., Martz, J. M., \& Agnew, C. R. (1998). The investment model scale: Measuring commitment level, satisfaction level, quality of alternatives, and investment size. Personal Relationships, 5, 357-391.

Schmiedeberg, C., \& Schröder, J. (2016). Does sexual satisfaction change with relationship duration? Archives of Sexual Behavior, 45, 99-107.

Sheff, E. (2013). The polyamorists next door: Inside multiple partner relationships and families. Lanham, MD: Rowman \& Littlefield. 
Sims, K. E., \& Meana, M. (2010). Why did passion wane? A qualitative study of married women's attributions for declines in sexual desire. Journal of Sex and Marital Therapy, 36, 360-380.

Simpson, J. A. (1987). The dissolution of romantic relationships: Factors involved in relationship stability and emotional distress. Journal of Personality and Social Psychology, 53, 683692.

Simon, R. W. (2002). Revisiting the relationships among gender, marital status, and mental health. American Journal of Sociology, 107, 1065-1096.

Smith, T. W. (1994). The demography of sexual behavior. Menlo Park, CA: Kaiser Family Foundation.

Sprecher, S. (2002). Sexual satisfaction in premarital relationships: Associations with satisfaction, love, commitment and stability. Journal of Sex Research, 39, 190-196.

Sprecher, S. \& Regan, P. C. (1998). Passionate and companionate love in courting and young married couples. Sociological Inquiry, 68, 163-185.

StataCorp. 2015. Stata Statistical Software: Release 14. College Station, TX: StataCorp LP.

Tennov, D. (1979). Love and limerance: The experience of being in love in New York. New York, NY: Stein and Day.

Wegner, D. M., Lane, J. D., \& Dimitri, S. (1994). The allure of secret relationships. Journal of Personality and Social Psychology, 66, 287-300.

Winston, R. (2004). Human. London, EN: Dorling Kindersley.

Yabiku, S., \& Gager, C. (2009). Sexual frequency and the stability of marital and cohabiting unions. Journal of Marriage \& the Family, 71, 983-1000. 
Yeh, H.-C., Lorenz, F. O., Wickrama, K. A. S., Conger, R. D., \& Elder, G. H. (2006).

Relationships among sexual satisfaction, marital quality, and marital instability at midlife. Journal of Family Psychology, 20, 339-343.

van Anders, S. M. (2015). Beyond sexual orientation: Integrating gender/sex and diverse sexualities via sexual configurations theory. Archives of Sexual Behavior, 44, 1177-1213.

van Anders, S. M., Goldey, K. L., \& Kuo, P. X. (2011). The steroid/ peptide theory of social bonds: Integrating testosterone and peptide responses for classifying social behavioral contexts. Psychoneuroendocrinology, 36, 1265-1275.

Veaux, F. (2011). Care and feeding of polyamorous secondary relationships. More Than Two. Retrieved from https://www.morethantwo.com/primarysecondary.html.

Veaux, F., Hardy, J., \& Gill, T. (2014) More than two: A practical guide to ethical polyamory. Portland, OR: Thorntree Press, LLC.

Wright, P. J., Tokunaga, R. S., Kraus, A., \& Klann, E. (2017). Pornography consumption and satisfaction: A meta-analysis. Human Communication Research, 43, 315-343. 
Running Head: EROTICISM VERSUS NURTURANCE

\section{Tables}

Table 1.

Demographic Information for Study 1 (Polyamorous) and Study 2 (Monogamous) Participants

\begin{tabular}{|c|c|c|}
\hline & Study $1-n(\%)$ & Study $2-n(\%)$ \\
\hline \multicolumn{3}{|l|}{ Gender Identity } \\
\hline Woman / females & $781(60.6 \%)$ & $1,496(68.5)$ \\
\hline Man / males & $330(25.6 \%)$ & $680(31.2)$ \\
\hline Gender-queer/Non-binary & $134(10.4 \%)$ & $2(0.1)$ \\
\hline Agender & $27(2.1 \%)$ & - \\
\hline Transgender & - & $5(0.2)$ \\
\hline Other & $16(1.2 \%)$ & - \\
\hline \multicolumn{3}{|l|}{ Race* } \\
\hline White & $1097(85.2 \%)$ & $1643(75.6 \%)$ \\
\hline Multi-Racial & $66(5.1 \%)$ & $80(3.7 \%)$ \\
\hline African American & $38(3.0 \%)$ & $121(5.6 \%)$ \\
\hline Asian (includes South, East or Southeast Asian) & $25(1.9 \%)$ & $80(3.7 \%)$ \\
\hline Hispanic (includes Caribbean / South American) & $23(1.8 \%)$ & $134(6.2 \%)$ \\
\hline Native American / Pacific Islander / First Nations & $13(1.1 \%)$ & $70(3.2 \%)$ \\
\hline Other & $25(1.9 \%)$ & $46(2.1 \%)$ \\
\hline \multicolumn{3}{|l|}{ Sexual Orientation } \\
\hline Heterosexual & $399(31.0 \%)$ & $2011(92.2)$ \\
\hline Lesbian / Gay & $37(2.9 \%)$ & $40(1.8)$ \\
\hline Bisexual & $556(43.2 \%)$ & $89(4.1)$ \\
\hline Asexual & $15(1.2 \%)$ & - \\
\hline Other & $281(21.8 \%)$ & $41(1.9)$ \\
\hline \multicolumn{3}{|l|}{ Relationship Status } \\
\hline Single & $30(2.3 \%)$ & - \\
\hline Casually dating & $78(6.1 \%)$ & $13(0.6)$ \\
\hline Seriously dating & $443(34.4 \%)$ & $234(10.7)$ \\
\hline Engaged & $79(6.1 \%)$ & $131(6.0)$ \\
\hline Married & $432(33.5 \%)$ & $1801(82.5)$ \\
\hline Divorced & $10(0.8 \%)$ & $4(0.2)$ \\
\hline Widowed & $3(0.2 \%)$ & - \\
\hline Other & $213(16.5 \%)$ & - \\
\hline \multicolumn{3}{|l|}{ Primary Partner } \\
\hline Primary Relationship & $521(44.6 \%)$ & - \\
\hline Primary relationship but have others & $224(19.2 \%)$ & - \\
\hline Not a primary & $56(4.8 \%)$ & - \\
\hline Do not believe in one as primary & $328(28.1 \%)$ & - \\
\hline Other & $39(3.3 \%)$ & - \\
\hline \multicolumn{3}{|l|}{ Secondary Partner } \\
\hline Primary Relationship & $17(1.6 \%)$ & - \\
\hline Primary relationship but have others & $224(21.7 \%)$ & - \\
\hline
\end{tabular}


Not a primary

$456(44.1 \%)$

Do not believe in one as primary

$310(30.0 \%)$

Other

$27(2.6 \%)$

Note: * indicates the column may add up to more than the total, since participants can select more than one option. Others may not add up to totals due to missing data. 
Table 2.

Summary of the Correlations, Means, and Standard Deviations of the Focal Variables for Polyamorous Participants

\begin{tabular}{|c|c|c|c|c|c|c|c|c|c|}
\hline & 1 & 2 & 3 & 4 & 5 & 6 & 7 & $M$ & $S D$ \\
\hline Nurturance Primary (1) ${ }^{1}$ & & & & & & & & $6.18^{2}$ & 1.07 \\
\hline Nurturance Secondary (2) & $.17 * * *$ & & & & & & & 5.05 & 1.51 \\
\hline Eroticism Primary (3) & $.20 * * *$ & $.48 * * *$ & & & & & & $4.83^{2}$ & 1.89 \\
\hline Eroticism Secondary (4) & $.13 * *$ & $.47 * * *$ & $.10 * *$ & & & & & 5.67 & 1.64 \\
\hline Closeness Primary (5) & $.46 * * *$ & .06 & .06 & $12 * *$ & & & & $5.55^{2}$ & 1.48 \\
\hline Closeness Secondary (6) & .07 & $.53 * * *$ & $.26 * * *$ & $.18 * * *$ & $.39 * * *$ & & & 4.24 & 1.64 \\
\hline Sexual Satisfaction Primary (7) & $.18 * * *$ & -.05 & $.45 * * *$ & -.06 & $.08 *$ & -.04 & & $5.67^{2}$ & 1.58 \\
\hline Sexual Satisfaction Secondary (8) & .09 & $.38 * * *$ & .04 & $.53 * * *$ & .05 & $.20 * * *$ & .06 & 5.94 & 1.35 \\
\hline
\end{tabular}

$* * * p<.001 ; * * p<.01 ; * p<.05$

${ }^{1}$ The results presented are for the overall sample (e.g., collapses across primary status).

${ }^{2}$ Participants report significantly higher nurturance $(p<.001)$ and closeness $(p<.001)$ for primary compared to secondary partners, though reports for eroticism $(p<.001)$ and sexual satisfaction $(p=.002)$ were higher among secondary partners compared to primary partners. 
Running Head: EROTICISM VERSUS NURTURANCE

Table 3 .

Summary of the Correlations, Means, and Standard Deviations of the Focal Variables for Monogamous Participants

\begin{tabular}{llllll}
\hline & 1 & 2 & 3 & $M$ & $S D$ \\
\hline Nurturance Mono (1) & & & & 5.85 & 1.32 \\
Eroticism Mono (2) & $.83^{* * *}$ & & & 5.16 & 1.60 \\
Closeness Mono (3) & $.59^{* * *}$ & $.59^{* * *}$ & & 5.26 & 1.78 \\
Sexual Satisfaction Mono (4) & $.79^{* * *}$ & $.63^{* * *}$ & $.53^{* * *}$ & 5.42 & 1.68 \\
\hline
\end{tabular}

$* * * p<.001 ; * * p<.01 ; * p<.05$ 
Running Head: EROTICISM VERSUS NURTURANCE

Table 4.

Comparisons of Mean Differences Between Monogamous and Polyamorous Ratings for Eroticism and Nurturance

\begin{tabular}{|c|c|c|c|c|c|c|c|c|}
\hline & \multicolumn{4}{|c|}{$\underline{\text { Nurturance }}$} & \multicolumn{4}{|c|}{$\underline{\text { Eroticism }}$} \\
\hline & Difference & $d f$ & $t$ & Cohen's $d$ & Difference & $d f$ & $t$ & Cohen's d \\
\hline \multicolumn{9}{|l|}{ Overall Sample } \\
\hline Mono - Primary & $0.33^{* *}$ & 2924 & 6.18 & 0.26 & $-0.33 * *$ & 2924 & -4.63 & 0.20 \\
\hline Mono - Secondary & $-0.80^{* *}$ & 2846 & -13.25 & 0.58 & $0.51 * *$ & 2846 & 7.27 & 0.32 \\
\hline Primary - Secondary & $1.18 * *$ & 679 & 17.76 & 0.68 & $-0.82 * *$ & 679 & -8.64 & 0.33 \\
\hline \multicolumn{9}{|l|}{ Primary-Secondary } \\
\hline Mono - Primary & $0.63 * *$ & 2426 & 7.49 & 0.49 & $-0.24 *$ & 2426 & -2.28 & 0.15 \\
\hline Mono - Secondary & $-1.47 * *$ & 2425 & -16.66 & 1.10 & $0.52 * *$ & 2425 & 4.89 & 0.32 \\
\hline Primary - Secondary & $2.10 * *$ & 258 & 20.79 & 1.29 & $-0.76^{* *}$ & 258 & -4.97 & 0.31 \\
\hline \multicolumn{9}{|l|}{ Co-Primary } \\
\hline Mono-Pseudo - Primary & $0.56^{* *}$ & 2302 & 4.89 & 0.43 & $-0.60 * *$ & 2302 & -4.17 & 0.37 \\
\hline Mono-Pseudo - Secondary & -0.08 & 2302 & -0.72 & 0.06 & $0.67 * *$ & 2302 & 4.77 & 0.42 \\
\hline Pseudo-Primary- Secondary & $0.64 * *$ & 135 & 6.45 & 0.55 & $-1.27 * *$ & 135 & -6.17 & 0.53 \\
\hline \multicolumn{9}{|l|}{ Non-Primary } \\
\hline Mono-Pseudo - Primary & 0.04 & 2355 & 0.41 & 0.03 & $-0.30 *$ & 2355 & -2.41 & 0.18 \\
\hline Mono-Pseudo - Secondary & $-0.50 * *$ & 2355 & -4.96 & 0.37 & $0.41 * *$ & 2355 & 3.37 & 0.26 \\
\hline Pseudo-Primary-Secondary & $0.54 * *$ & 188 & 4.56 & 0.33 & $-0.71 * *$ & 188 & -3.83 & 0.28 \\
\hline
\end{tabular}

*indicates a significant difference at $p<.05 ; * *$ indicates a significant difference at $p<.001$

Note. Difference represents the mean difference of comparisons and the effect sizes presented are based on independent $t$-tests for monogamous and polyamorous comparisons, and dependent $t$-tests for polyamorous comparisons. The degrees of freedom vary in each analysis due to missing data points. 
Running Head: EROTICISM VERSUS NURTURANCE

Table 5 .

Regression Estimates of Differences Between Monogamous and Polyamorous Ratings for Partners Adjusted for Gender Identity, Sexual Orientation, and Relationship Length

\begin{tabular}{|c|c|c|c|c|c|c|}
\hline & \multicolumn{3}{|c|}{ Nurturance } & \multicolumn{3}{|c|}{$\underline{\text { Eroticism }}$} \\
\hline & $B$ & $S E$ & $t$ & $B$ & $S E$ & $t$ \\
\hline \multicolumn{7}{|l|}{ Overall Sample } \\
\hline Mono - Primary & $0.27 * *$ & 0.07 & 3.72 & $-0.65 * *$ & 0.09 & -6.88 \\
\hline Mono - Secondary & -0.86 & 0.08 & -10.10 & $0.28 * *$ & 0.10 & 2.83 \\
\hline Primary - Secondary & $-1.13 * *$ & 0.07 & -16.45 & $0.85 * *$ & 0.09 & 9.16 \\
\hline \multicolumn{7}{|l|}{ Primary-Secondary } \\
\hline Mono-Primary & $0.57 * *$ & 0.10 & 5.91 & $-0.54 * *$ & 0.13 & -4.32 \\
\hline Mono-Secondary & $-1.52 * *$ & 0.11 & -14.30 & 0.23 & 0.13 & 1.82 \\
\hline Primary-Secondary & $-2.10 * *$ & 0.11 & -19.62 & $0.76 * *$ & 0.15 & 5.02 \\
\hline \multicolumn{7}{|l|}{ Co-Primary } \\
\hline Mono - Pseudo-Primary & $0.50 * *$ & 0.12 & 4.06 & $-0.90 * *$ & 0.16 & -5.63 \\
\hline Mono - Pseudo-Secondary & -0.14 & 0.13 & -1.08 & $0.43 * *$ & 0.16 & 2.76 \\
\hline Pseudo-Primary-Secondary & $-0.64 * *$ & 0.11 & -5.62 & $1.27 * *$ & 0.20 & 6.28 \\
\hline \multicolumn{7}{|l|}{ Non-Primary } \\
\hline Mono-Pseudo - Primary & -0.05 & 0.11 & -0.42 & $-0.66 * *$ & 0.15 & -4.49 \\
\hline Mono-Pseudo - Secondary & $-0.58 * *$ & 0.12 & -4.67 & 0.22 & 0.15 & 1.48 \\
\hline Pseudo-Primary - Secondary & $-0.54 * *$ & 0.14 & -4.00 & $0.71 * *$ & 0.19 & 3.78 \\
\hline
\end{tabular}

*indicates a significant difference at $p<.05 ; * *$ indicates a significant difference at $p<.001$

${ }^{1}$ The comparison for monogamous partners and secondary partners in primary-secondary relationships ( $p=.07$ ) was marginal when gender identity, sexual orientation, and relationship length is controlled for, while the comparison for monogamous partners and pseudo-secondary partners in non-primary relationships is no longer significant $(p=.13)$. 
Figure 1a. Mean Ratings for Nurturance

7

6

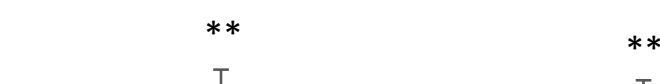

5

4

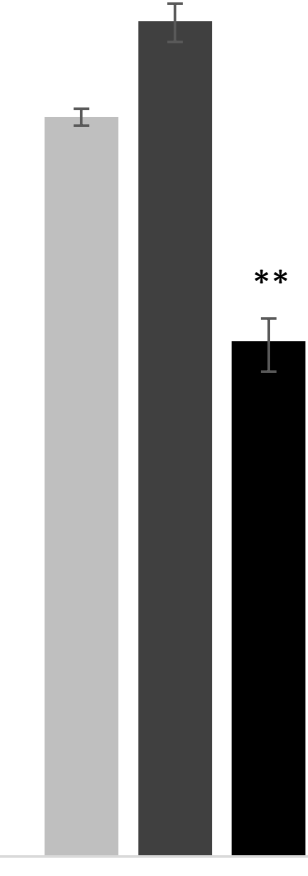

3

2

1

Primary-Secondary

Co-Primary
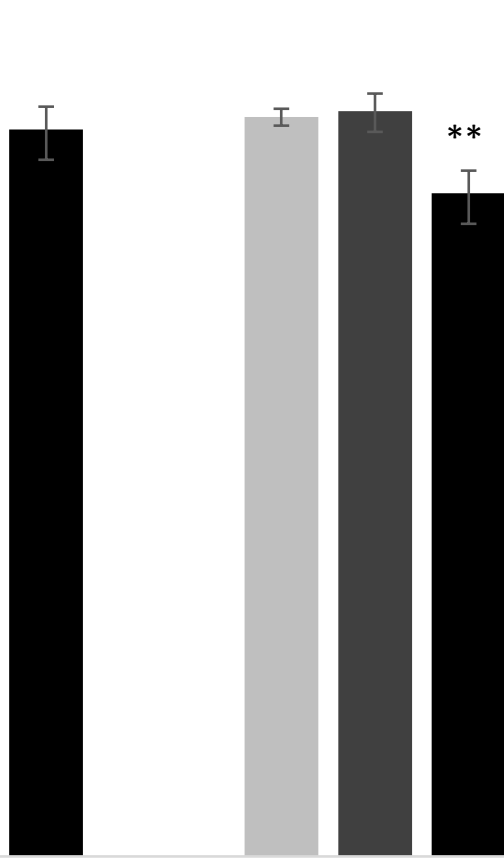

Non-Primary

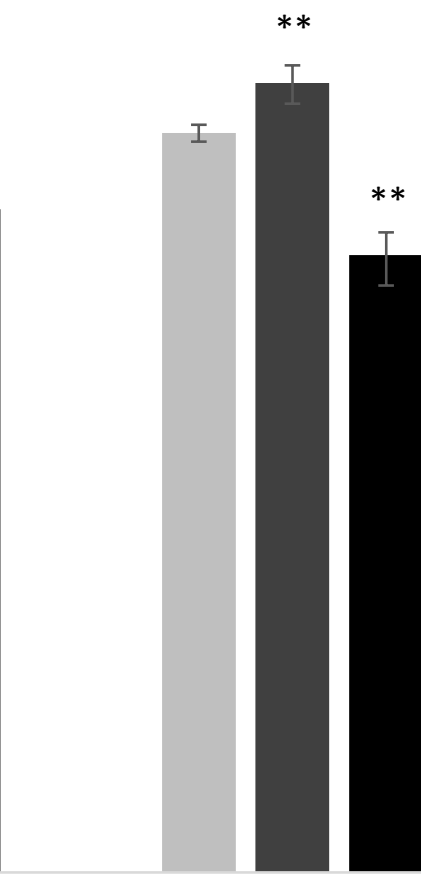

Monogamous Partner

- Primary Partner

- Secondary Partner

$* * p<.01 ; * p<.05$.

Note: Presented are ratings for polyamorous partners across the varying configurations and in comparison to monogamous partners. All mean ratings were unadjusted for other demographic factors. 
Figure 1b. Mean Ratings for Eroticism

7

6

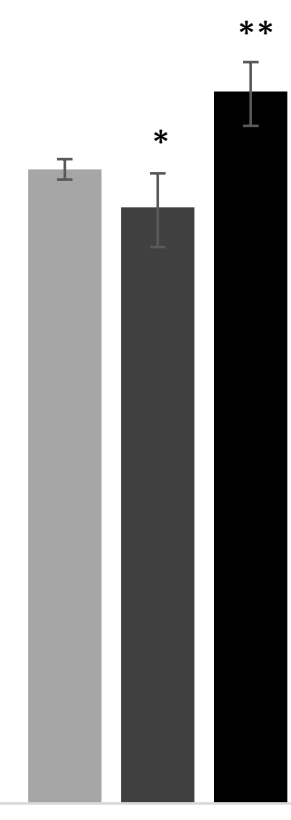

Primary-Secondary

Co-Primary

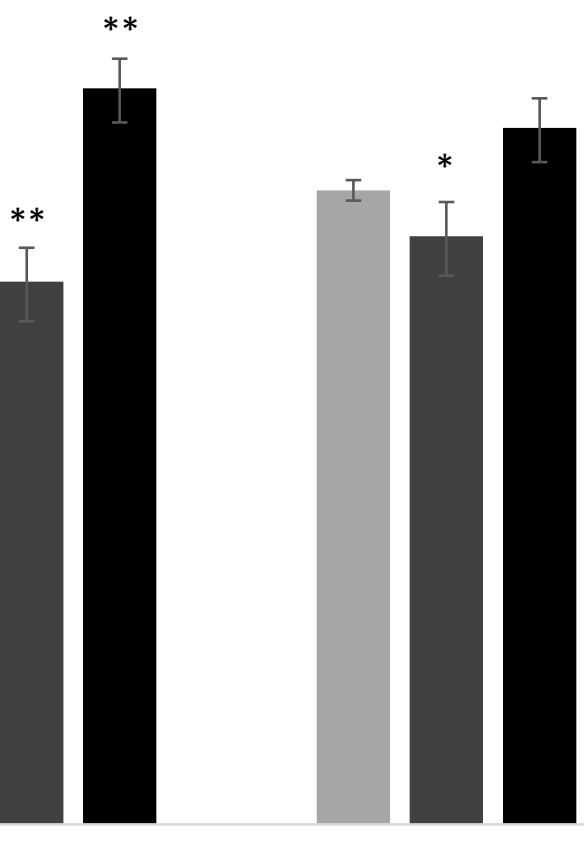

- Monogamous Partner

- Primary Partner

- Secondary Partner

3

2

1

Non-Primary

Overall Sample

$* * p<.01 ; * p<.05$.

Note: Presented are ratings for polyamorous partners across the varying configurations and in comparison to monogamous partners. All mean ratings were unadjusted for other demographic factors. 